\title{
Nickel-Catalyzed Enantioselective 1,1-Arylboration of Unactivated Olefins
}

\section{Key words}

nickel catalysis

arylation

borylation

enantioselectivity

regioselectivity

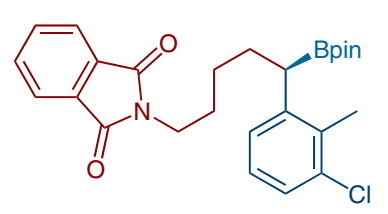

$85 \%$ yield, $96 \%$ ee

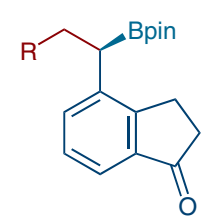

$\mathrm{R}=\mathrm{Cy}, 84 \%$ yield, $96 \%$ ee $\mathrm{R}=\mathrm{Me}, 58 \%$ yield, $94 \%$ ee

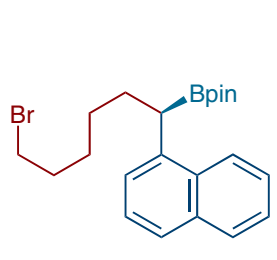

$53 \%$ yield, $94 \%$ ee
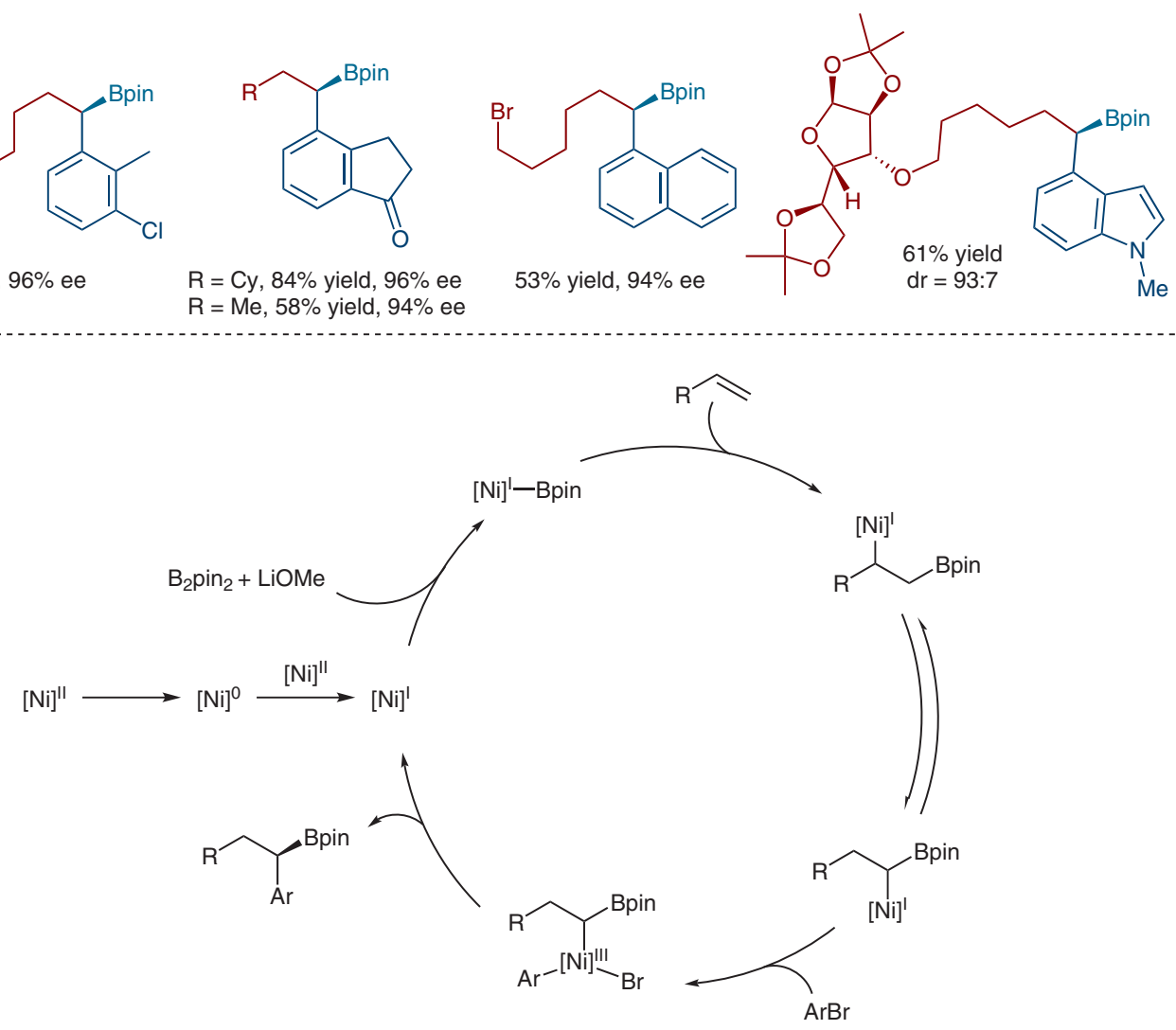

Significance: An enantioselective method for the 1,1 -arylboration of unactivated olefins using a simple nickel-diamine catalyst is reported. A range of olefins were employed from ethylene and propylene to olefins containing tethered Lewis basic heteroatoms or reactive $1^{\circ}$ alkyl halides.
Comment: The regioselectivity of the reaction was demonstrated to be catalyst controlled. A mechanism involving an initial 1,2-insertion of a $\mathrm{Ni}$-Bpin species is reported. The proposed catalytic cycle was supported by a variety of mechanistic studies including a deuterium labeling study. 